\title{
Epidemiologic Evidence and Motor Vehicle Policy Making
}

\author{
Carol W. Runyan, MPH, PhD, and Jo Anne L. Earp, ScD
}

\begin{abstract}
After being randomly assigned to receive policy effectiveness information expressed as attributable benefit, attributable risk, or relative risk, 318 graduate students were asked to indicate their preferences for the current voluntary seat belt use policy, a mandatory seat belt policy, or mandatory passive restraints. A control group received no data. Exposure to effectiveness information (any type) was significantly associated with favor-
\end{abstract}

ing either mandatory seat belts or passive restraints over the current policy. Those exposed to attributable benefit or risk data were more apt to make proregulatory choices than subjects exposed to relative risk data. Attitudes toward government regulation and specific views about personal freedom and policy effectiveness were also found to be significant predictors of policy preference. (Am J Public Health 1985; 75:354-357.)

\section{Introduction}

Epidemiologic conventions concerning the use of data are dictated by the statistical meanings of different data types. ${ }^{1}$ Relative risk is typically used to express information about the mechanism of disease or trauma. Attributable risk, in contrast, provides information about the effect on a population of modifying exposure to a risk factor once a "causal" mechanism has been established. ${ }^{1.2}$ Hence, it has been recommended that attributable risk (or attributable benefit) data be employed in communications about the potential effectiveness of various policies, especially in reference to more frequently occurring health problems; motor vehicle-related trauma is a case in point..$^{1.3}$

The psychological literature on decision making suggests that data are interpreted differently depending on how they are stated. ${ }^{4}$ Data that express greater certainty are favored by decision makers. Also, persons presented with equivalent evidence about deleterious versus beneficial outcomes choose "safer" policy options when the evidence is stated as "lives saved" versus "lives lost." 4 This study was designed to determine: a) if policy preferences would be influenced by exposure to data about policy effectiveness; and b) if different types of data would elicit different preferences.

We expected that an estimate of the absolute number of individuals who would experience injury or death (or be saved from injury or death) would appear more certain, and result in the choice of safer (i.e., more effective) policies than information about the relative probability (relative risk) of each negative outcome. Furthermore, we hypothesized that presenting subjects with data about lives saved or injuries averted (i.e., benefits attributable to each policy) versus lives lost or injuries suffered (i.e., risks attributable to each policy) would result in the selection of more effective motor vehicle policies.

The purpose of this study, conducted between November 1982 and January 1983, was to compare differences in policy preferences as a result of exposure to: 1) any vs no data; 2) absolute vs relative data (attributable vs relative risk); and 3) benefit vs risk data. We also examined the role

Address reprint requests to Dr. Carol W. Runyan, Research Assistant Professor, Department of Social and Administrative Medicine, School of Medicine, Wing D Old Nurses Dorm, University of North Carolina, Chapel Hill, NC 27514. Dr. Earp is with the Department of Health Education, School of Public Health, University of North Carolina. This paper, submitted to the Journal July 9, 1984, was revised and accepted for publication October 2. 1984.

Editor's Note: See also related editorial p 340 this issue.

(C) 1985 American Journal of Public Health 0090-0036/85 $\$ 1.50$ of attitudinal differences and personal experiences since the risk perception and policy analysis literatures suggest that these characteristics influence policy decisions. ${ }^{5-7}$ Finally, we wanted to know whether mortality versus morbidity information would affect policy preferences.

\section{Methods}

A sample of graduate students in law $(\mathrm{N}=173)$ and business administration $(\mathrm{N}=145)$ volunteered* to consider data about the effectiveness of three policy options:

- the required installation of passive restraints (airbags or automatic seat belts) in all cars;

- mandatory seat belt use; and

- voluntary seat belt use (the current policy).

These particular student groups were chosen because business and law are the two professions most often represented in legislative bodies. ${ }^{8}$ Each group was representative of the total student population from which it was drawn. The sample was 92 per cent White, 57 per cent male, with a mean age of 26; 74 per cent had parents who had achieved at least a college education.

Subjects were randomly assigned to seven groups representing six experimental and one control condition. The experimental manipulation consisted of the presentations of data about policy effectiveness with data format (attributable benefit, attributable risk and relative risk) crossed with content (mortality, morbidity) in a $3 \times 2$ factorial design.** Instead of being exposed to data about policy effectiveness, subjects in the control group were presented with brief descriptions of the three policies. The data statements and policy descriptions were embedded in a 20 -minute selfadministered questionnaire completed by all 318 subjects. Calculations of data figures are shown in Appendix I. Appendix II demonstrates how the data were presented to the different groups.

Variables

Policy preference, the dependent variable, was derived from each subject's rating of all three policies on a single 10point scale from "strongly oppose" to "strongly favor." It was dichotomized as follows: "pro-regulatory" if either or both regulatory options (automatic restraints or mandatory

*Junior and senior law students were asked to stay after class to complete a questionnaire which was described in advance as a survey about health policy. Second year MBA students in four required courses participated during class time.

**Attributable risk, as used in this study, refers to the risk difference (expected frequency in the exposed minus the expected frequency in the unexposed). 1 
seat belt use) received a rating more favorable than the current policy, and "anti-regulatory" if the current policy was rated most favorably of the three.

In addition, the questionnaire included items measuring subjects' attitudes toward other governmental health regulations (a summated scale); prior crash experience; seat belt use; perceptions of personal risk and benefits about the importance of considering evaluative criteria such as the effectiveness of the policy, limitations on personal freedom, implementation costs, equity across population subgroups, and public preferences. Each of the evaluative criteria was measured on a 10-point scale from "extremely unimportant" to "extremely important"; subjects were asked to "rate the importance of each [criterion] to the evaluation of motor vehicle safety policies."'

\section{Results}

Subjects in the six experimental groups were almost three times more likely than control subjects $(60$ per cent vs 22 per cent) to choose one of the regulatory policies, i.e., those receiving any form of effectiveness data preferred either or both of the regulatory policies over the current policy in contrast to those who received no effectiveness data (Table 1).

Sixty-four per cent of subjects in the attributable data groups vs 52 per cent receiving relative risk data chose one of the regulatory policies (Table 2 ).

There were no significant differences between subjects in the attributable benefit versus attributable risk groups nor in the mortality versus morbidity comparisons. No interaction effects between data format (attributable risk, attributable benefit, relative risk) and data content (mortality, morbidity) were found.

A multivariable stepwise regression procedure revealed that four additional variables were significant predictors of subjects' policy preferences: 1) their perceived risks of ever being involved in a serious crash; 2) their attitudes toward other governmental health regulations; 3 ) their views on the importance of including personal freedom; and 4) their views on policy effectiveness as policy analysis criteria (Table 3 ). The more subjects considered the issue of personal freedom to be an important criterion in safety policy making, the less likely they were to favor either a seat belt law or the required installation of automatic restraints. On the other hand, the more important a policy's effectiveness was considered to be, the more proregulatory the policy preferences. Subjects' assessments of their own risks of ever being in a serious

TABLE 1-Policy Preference by Data Exposure

\begin{tabular}{|c|c|c|c|c|c|c|}
\hline \multirow{3}{*}{ Policy Preference } & \multicolumn{6}{|c|}{ Data Exposure } \\
\hline & \multicolumn{2}{|c|}{ Data } & \multicolumn{2}{|c|}{ No Data } & \multicolumn{2}{|c|}{ Total } \\
\hline & $\#$ & $(\%)$ & $\#$ & (\%) & \# & $(\%)$ \\
\hline $\begin{array}{l}\text { Current Policy } \\
\text { (voluntary seat belt } \\
\text { use) }\end{array}$ & 108 & (40) & 38 & (78) & 146 & (46) \\
\hline $\begin{array}{l}\text { Regulatory Policy } \\
\text { mandatory seat belt } \\
\text { use or automatic }\end{array}$ & & & & & & \\
\hline $\begin{array}{l}\text { restraints) } \\
\text { Totals }\end{array}$ & $\begin{array}{l}161 \\
269\end{array}$ & $\begin{array}{r}(60) \\
(100)\end{array}$ & $\begin{array}{l}11 \\
49\end{array}$ & $\begin{array}{r}(22) \\
(100)\end{array}$ & $\begin{array}{l}172 \\
318\end{array}$ & $\begin{array}{r}(54) \\
(100)\end{array}$ \\
\hline
\end{tabular}

Chi square $=23.25 \quad p<.001$
TABLE 2-Policy Preference by Attributable vs Relative Risk Formats

\begin{tabular}{|c|c|c|c|c|c|c|}
\hline \multirow{3}{*}{ Policy Preference } & \multicolumn{6}{|c|}{ Data Formats } \\
\hline & \multicolumn{2}{|c|}{$\begin{array}{l}\text { Attributable } \\
\text { Formats }\end{array}$} & \multicolumn{2}{|c|}{$\begin{array}{l}\text { Relative Risk } \\
\text { Format }\end{array}$} & \multicolumn{2}{|c|}{ Total } \\
\hline & $\#$ & $(\%)$ & $\#$ & (\%) & $\#$ & (\%) \\
\hline $\begin{array}{l}\text { Current Policy } \\
\text { (voluntary seat belt } \\
\text { use) } \\
\text { Regulatory Policy } \\
\text { (mandatory seat belt } \\
\text { use or automatic } \\
\text { restraints) }\end{array}$ & 112 & (36) & 45 & (48) & 108 & (40) \\
\hline Totals & 175 & $(100)$ & 94 & $(100)$ & 269 & $(100)$ \\
\hline
\end{tabular}

Chi square $=3.58 \quad p=.058$

crash and their favorable views toward other governmental health regulations were positively associated with choosing one of the regulatory policies over the current policy. These relationships were observed even when exposure to data (vs no data) was controlled. All together, these four variables accounted for 23 per cent of the variance in policy preference. Exposure to data (the experimental manipulation) explained an additional 7 per cent of the total variance.

Personal crash experience (either the subjects' own or that of a close friend or relative) did not predict policy preference. Similarly, the perceived importance of considering the policy analysis criteria of cost, equity, or public preferences did not predict anti-regulatory versus pro-regulatory policy preferences.

\section{Discussion}

Data about policy effectiveness do appear to influence judgments about motor vehicle safety policies. However, contrary to conventional epidemiologic wisdom and the study's hypotheses, the specific form of data appears to be less important. Although the results of this study are not conclusive, they support, albeit modestly, the theoretical evidence that decision makers prefer data appearing to express more certain outcomes (i.e., the absolute numbers in attributable data) over data expressed in terms of relative probabilities. It is clear, however, that data alone do not determine policy choices. Personal experiences, attitudes, and beliefs also play an important role in decision making.

We were surprised to find no differences in policy preference as a function of exposure to morbidity compared to mortality information. Perhaps the importance of death as a more absolute outcome was counterbalanced by the salience and magnitude of the morbidity figures, especially among this relatively youthful sample whose experiences

TABLE 3-Regression Predicting Policy Preference

\begin{tabular}{lccr}
\hline \multicolumn{1}{c}{ Variable } & $\begin{array}{c}\text { Beta Weight } \\
\text { (unstandardized) }\end{array}$ & $\begin{array}{r}\text { R Square } \\
\text { Increment }\end{array}$ & p Value \\
\hline Personal freedom & -.05 & .12 & $<.001$ \\
Policy effectiveness & .07 & .07 & $<.001$ \\
$\begin{array}{l}\text { Perceived risk } \\
\text { Attitudes toward } \\
\text { government regulation }\end{array}$ & .003 & .03 & .006 \\
TOTAL & .005 & .01 & .015 \\
\hline
\end{tabular}


with non-fatal injuries is undoubtedly greater than with death. Even more unexpectedly, prior crash experiences did not significantly predict subjects' policy preferences.

Although selected to approximate the professional backgrounds of actual legislators, our use of a student sample-which is more homogeneous, younger, and less politically savvy than actual legislators-raises questions about the generalizability of the results. While the experimental design permits greater confidence in the internal validity of the findings, it is obviously at the expense of testing the hypotheses in a real-life policy-making arena. Measurement within a restricted, experimental context may mask the identification of additional "natural" variables of socio-political importance. Similarly, the measurement of preferences in this study differs from the use of actual decision making as the outcome. Just as preferences are influenced by many factors, actual policy decisions (or votes for legislation) are even more subject to outside pressures and hence may not always conform to decision makers' preferences.

The use of epidemiologic research to inform the public policy process is fraught with difficulties. Policy makers are expected to make timely decisions using the best available evidence, but they often are exasperated by scientists' equivocation. Researchers, in turn, are reluctant to draw unequivocal conclusions about their inherently probabilistic and uncertain findings. Many investigators are skeptical about whether policy makers even try to use the research information they do receive.

The specific form that data should take to have the greatest impact obviously depends on the type of data actually available, characteristics of the audience receiving the report, the nature of the health problem or policies under consideration and, undoubtedly, a host of other factors. Perhaps the observed differences between the effects of attributable data and relative risk data do not hold in considering policies that deal with rare diseases or events; that is, when a given agent may be an important cause of a health problem (high relative risk) but few people are affected by virtue of the rarity of the problem (low attributable risk).

We can conclude from this research, however, that the "hard facts" garnered by public health researchers will inevitably be interpreted through "value-colored" glasses. How the public health researcher reconciles this fact may differ from how the public health advocate does so. Both need to be cognizant of the dual role played by scientific "facts" and personal values in the policy decision-making process. Further research in natural settings is necessary to illuminate how scientific information is most effectively communicated to the public and convincingly conveyed to policy makers.

\section{REFERENCES}

1. Kleinbaum D, Kupper L, Morgenstern H: Epidemiologic Research: Principles and Quantitative Methods. Belmont, CA: Lifetime Learning Publications, 1982

2. Editorial: Relative or attributable risk? Lancet 1981; 2(8257):1211-1212.

3. MacMahon D, Pugh T: Epidemiology: Principles and Methods. Boston: Little, Brown, \& Co, 1970.

4. Tversky A, Kahneman D: The framing of decisions and the psychology of choice. Science 1981; 211:453-458

5. Starr C, Whipple C: The risks of risk decisions. Science 1980; 208:11141119.

6. Fischhoff B, Lichtenstein S, Slovic P, Derby S, Keeney R: Acceptable Risk. New York: Cambridge University Press, 1981.
7. MacRae D, Wilde J: Policy analysis for public decisions. N. Scituate, MA: Duxbury Press, 1979.

8. Cheney J: North Carolina Manual 1981-1982. Raleigh: Secretary of State's Office, 1982.

9. National Safety Council: Accident Facts. Chicago: National Safety Council, 1982.

10. Robertson L: Automobile seat belt use in selected countries and provinces with and without laws requiring belt use. Accident Anal Prev 1978; 10:5-10.

\section{ACKNOWLEDGMENTS}

The authors wish to thank the following individuals for their help in conceptualizing, executing and/or reporting this work: B. M. De Vellis R. F. DeVellis, G. M. Hochbaum, B. H. Kaplan, D. K. Runyan, A. P. Schenck, V. J. Schoenbach, D. S. Strogatz, P. L. Waller. The senior author was supported in part by a fellowship from the Bush Foundation, St. Paul, Minnesota. This material was presented at the 111th Annual Meeting of the American Public Health Association, Dallas, Texas, November 1983.

\section{APPENDIX I}

\section{CALCULATIONS OF DATA FIGURES* (Annual United States Statistics)}

Current Policy

Mortality $=27,400$ deaths

Morbidity $=239,750$ serious injuries and/or permanent disabilities

Mandatory Seat Belt Policy**

Attributable benefit, mortality $=27,400 \times 65 \%$ effective $\times 75 \%$ use Attributable benefit, morbidity $=239,750 \times 50 \%$ effective $\times 75 \%$ use Attributable risk, mortality $=27,400$ - (attributable benefit, mortality) Attributable risk, morbidity $=239,750-$ (attributable benefit, morbidity) Relative risk, mortality $=27,400 /(27,400 \times 65 \%$ effective $\times 75 \%$ use $)$ Relative risk, morbidity $=239,750 /(239,750 \times 50 \%$ effective $\times 75 \%$ use $)$

Automatic Restraint Policy

Attributable benefit, mortality $=27,400 \times 65 \%$ effective Attributable benefit, morbidity $=239,750 \times 50 \%$ effective Attributable risk, mortality $=27,400-$ (attributable benefit, mortality) Attributable risk, morbidity $=239,750$ - (attributable benefit, morbidity) Relative risk, mortality $=27,400 /(27,400 \times 65 \%$ effective $)$ Relative risk, morbidity $=239,750 /(239,750 \times 50 \%$ effective $)$

Mortality data are based on US data from the National Safety Council, 1982. Morbidity figures (derived from an 8:1 observed ratio of serious injury to death) and effectiveness figures were estimated by D. Reinfurt, North Carolina Highway Safety Research Center, 1982, personal communication. All figures represent adult occupants only.

"*Usage estimates are based on average rates in countries with mandatory seat belt policies. ${ }^{10}$

\section{APPENDIX \|}

\section{DATA STATEMENTS BY GROUP: THE EXPERIMENTAL MANIPULATION}

Imagine that you are a legislator considering three policies concerned with automobile safety. Read the description of each policy below [and consider carefully the effectiveness data that are presented].* You will then be asked to indicate your stance on each policy. For the time being, ignore that some measures may be more appropriately implemented at the state, federal or local level. All the data are based on estimates by the Highway Safety Research Center at the University of North Carolina and pertain to the entire United States.

Data as presented to the ATTRIBUTABLE BENEFIT, MORTALITY group

POLICY A: THE CURRENT POLICY-Under the current policy, auto manufacturers are required to install seat bealts in all new cars sold in the United States. Seat belt use is encouraged through a variety of educational programs funded by the government and by private organizations.

With this policy 27,400 people can be expected to die as occupants in automobile crashes in the United States in a given year. 
POLICY B: SEAT BELT LAW-A proposed policy would require that all persons riding in automobiles use seat belts. Failure to do so would result in a penalty.

With this policy it is estimated that 13,350 lives of occupants could be saved in automobile crashes in the United States in a given year, taking into account that some people (25\%) would not comply with the law.

POLICY C: AUTOMATIC RESTRAINTS-A proposed policy would require all new cars to have an automatic restraint system (airbags and/or automatic seat belts) installed by the manufacturer as standard equipment.

With this policy fully implemented it is estimated that 17,800 lives of occupants could be saved in automobile crashes in the United States in a given year.

NOTE: Variations in the wording below replaced the underlined segments of the data statements above except for the relative risk groups for policies B and $\mathrm{C}$. These two groups required more extensive changes in the text.

Data presented to the ATTRIBUTABLE BENEFIT, MORBIDITY group

POLICY A: “. . . 239,750 . . suffer serious injuries or permanent disabilities ..."

POLICY B: ". . . 89,900 serious injuries or permanent disabilities of occupants in automobile crashes could be averted ..."

POLICY C: ". . . 119,875 serious injuries or permanent disabilities of occupants in automobile crashes could be averted in the United States in a given year."

Data presented to the ATTRIBUTABLE RISK, MOTALITY group

POLICY A: " . . 27,400 . . . die ..."

POLICY B: ". . 14,050 . . . can be expected to die . . ."

POLICY C: “. . . 9,600 people can be expected to die . . ."
Data presented to the ATTRIBUTABLE RISK, MORBIDITY group

POLICY A: " . . 239,750 . . suffer serious injuries or permanent disabilities ..."

POLICY B: ". . . 149,850 people can be expected to suffer serious injuries or permanent disabilities ..."

POLICY C: “. . . 119,875 people can be expected to suffer serious injuries or permanent disabilities ..."

Data presented to the RELATIVE RISK, MORTALITY group

POLICY A: ". . . one in 8,000 people on the average, can be expected to die ..."

POLICY B: "The chances of being killed as an occupant in an automobile crash are 2.0 times greater under the current policy than with a seat belt law, taking into account ..."

POLICY C: "The chances of being killed as an occupant in an automobile crash are $\mathbf{2 . 8}$ times greater under the current policy than with an automatic restraint policy fully implemented."

Data presented to the RELATIVE RISK, MORBIDITY group

POLICY A: ". . . one in 1,000 people on the average, can be expected to suffer serious injuries or permanent disabilities ...."

POLICY B: "The chances of being seriously injured or permanently disabled in an automobile crash in the United States in a given year are 1.6 times greater under the current policy than with a seat belt law, taking into account ...."

POLICY C: "The chances of being seriously injured or permanently disabled as an occupant in an automobile crash in the United States in a given year are 2.0 times greater under the current policy than if an automatic restraint policy were fully implemented."

"The phrase in brackets was omitted for the control group which received only the policy descriptions and no data.

\section{ACS National Conference on Care of the Child with Cancer}

The American Cancer Society has announced its National Conference on Advances in the Care of the Child with Cancer, to be held June 12-14, 1985 at the Los Angeles Hilton in Los Angeles, California.

The continuing education objectives of this conference are to:

- review progress in the outcome of care for the child with cancer,

- report advances in treatment, supportive care and psychosocial management,

- promote the multidisciplinary approach for the child and family dealing with cancer, and

- identify new areas for investigation with pediatric cancer patients.

This continuing medical education activity meets the criteria for $15 \frac{1}{2}$ hours in Category I of the Physicians' Recognition Award of the American Medical Association. Continuing education credits will be requested from the following organizations: American Academy of Family Physicians, California Board of Registered Nursing and the California Chapter of National Association of Social Workers.

The meeting will be open to pediatricians, pediatric oncologists, primary care physicians, other specialists in oncology, students, and other health care professionals interested in child health care.

For further information write to: American Cancer Society, National Conference on Advances in the Care of the Child with Cancer, 777 Third Avenue, New York, NY 10017. 